\title{
Using LMDI Approach to Analyze Changes in Carbon Dioxide Emissions of China's Logistics Industry
}

\author{
Ying Dai, Jing Zhu, Han Song \\ College of Management, Chongqing University of Technology (China) \\ daijing@,cqut.edu.cn,_buangfang@,cqut.edu.cn, songhan@gmail.com
}

Received: March 2015

Accepted: June 2015

\section{Abstract:}

Purpose: China is confronting with tremendous pressure in carbon emission reduction. While logistics industry seriously relies on fossil fuel, and emits greenhouse gas, especially carbon dioxide. The aim of this article is to estimate the carbon dioxide emission in China's logistics sector, and analyze the causes for the change of carbon dioxide emission, and identify the critical factors which mainly drive the change in carbon dioxide emissions of China's logistics industry.

Design/methodology/approach: The logarithmic mean Divisia index (LMDI) method has often been used to analyze decomposition of energy consumption and carbon emission due to its theoretical foundation, adaptability, ease of use and result interpretation. So we use the LMDI method to analyze the changes in carbon dioxide emission of China's logistics industry in this paper.

Findings: By analyzing carbon dioxide emission of China's logistics, the results show that the carbon dioxide emission of logistics in China has increased by 21.5 times, from 45.1 million tons to 1014.1 million tons in the research period. The highway transport is the main contributor to carbon dioxide emission in logistics industry. The energy intensity and carbon dioxide emission factors contributed to the reduction of carbon dioxide emission in China's logistics industry in overall study period. 
Originality/value: Although a lot of literature have analyzed carbon dioxide emission in many industry sectors, such as manufacturing, iron and steel, pulp and paper, cement, glass industry, and so on. However, few scholars researched on carbon dioxide emission in logistics industry. This is the first study which is in the context of carbon dioxide emission of China's logistics industry.

Keywords: logistics industry in China, carbon dioxide emission, LMDI

\section{Introduction}

Many studies have suggested that the concentration of greenhouse gases (GHG) in the atmosphere has been increasing as a result of human activities (Loo \& Li, 2012), and the high concentration of GHG has caused global warming which was measured by the increase of the Earth's average temperature (Chapman, 2007). It was reported that the average global surface temperature had increased by $0.74^{\circ} \mathrm{C}$ over the last 100 years (2014), which was caused by the GHGin the atmosphere, due to the consumption of numerous fossil fuels. Intensive use of fossil fuels can be cited as the main reason of the significant increase in anthropogenic GHG that lead to climate change (Ipek-Tunç, Türüt-Aşık \& Akbostanci, 2009). Carbon dioxide $\left(\mathrm{CO}_{2}\right)$ was the most important composition and accounted for about $80 \%$ share of the greenhouse effect (Liao, Lu \& Tseng, 2011). Figure 1 shows the top five $\mathrm{CO}_{2}$ emission countries in the world. China has exceed America and become the first source of $\mathrm{CO}_{2}$ emission since 2007, with 8320.96 million tons carbon (MTC) in 2010, which accounted for $26.2 \%$ share of the total $\mathrm{CO}_{2}$ emission in the world (2014). As a signatory of the United Nations Framework Convention on Climate Change (UNFCCC), China approved the Kyoto Protocol in 2002, and promised that carbon emissions per unit of GDP would be reduced by $40 \%-45 \%$ in 2020 than 2005 in Copenhagen world climate meeting in 2009 . It is greatly significant for policy makers to analyze the change in dioxide carbon emission and find the critical factors to achieve the goal of emission reduction.

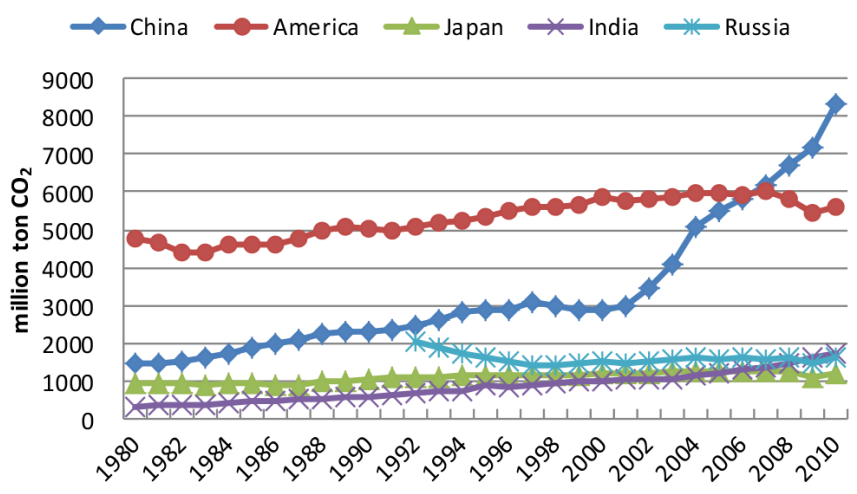

Figure 1. Top five of total $\mathrm{CO}_{2}$ emission in the world (U.S. Energy Information Administration, EIA, 2012) 
Confronted with global warming, $\mathrm{CO}_{2}$ emission as a main composition of GHG was widely paid attention and researched by most governments, scholars and enterprises in recent years. We can roughly summarize the researches as the following aspects. The first aspect primarily focused on the relationships between energy consumption, $\mathrm{CO}_{2}$ emission and economic activities in different countries and districts, such as China (Wang, Zhou \& Zhou, 2011), Russia (Pao, Yu \& Yang, 2011), India (Ghosh, 2010), Europe (Acaravcia \& Ozturk, 2010), South Africa (Menyah \& Wolde-Rufael, 2010), Turkey (Halicioglu, 2009), and so on. The research results showed there were different causal relationships in different countries. The second aspect was on the forecasting of $\mathrm{CO}_{2}$ emission. For example, Azadeh, Khakestani and Saberi (2009) forecasted the oil consumption and $\mathrm{CO}_{2}$ emission in Canada, United States, Japan and Australia during 1990-2005 by using a flexible fuzzy regression algorithm. Olsthoorn (2001) estimated $\mathrm{CO}_{2}$ emissions from international aviation from 1950 to 2050 through a regression model. Finally, it was case study of $\mathrm{CO}_{2}$ emission decomposition. For example, Ipek-Tunç et al. (2009) identified the factors that contributed to the changes in $\mathrm{CO}_{2}$ emissions in agriculture, industry and services. Hammond and Norman (2012) researched on carbon emissions from UK manufacturing between 1990 and 2007. Sheinbaum, Ozawa and Castillo (2010) analyzed energy and $\mathrm{CO}_{2}$ emission trends of Mexico's iron and steel industry during the period 1970-2006 using Log mean Divisia index; Schmitz, Kamiński, Scalet and Soria (2011) represented a detailed analysis of $\mathrm{CO}_{2}$ emissions and energy consumption of European glass industry. Xu, Tobias and Eichhammer (2012) analyzed the change of energy consumption and $\mathrm{CO}_{2}$ emissions in China's cement industry and its driving factors over the period 1990-2009.

As we know, transport is one of main resources of $\mathrm{CO}_{2}$ emissions. Some research achievements were made. Steenhof, Woudsman and Sparling (2006) analyzed the change in GHG emissions produced by Canada's freight transport using a decomposition analysis framework. Liao et al. (2011) examined $\mathrm{CO}_{2}$ emissions of truck-only transportation using activity-based emission modeling and compared those with intermodal coastal shipping and truck movements. Fatumata and Lee (2009) compared the energy intensity and $\mathrm{CO}_{2}$ emission of truck freight in Australia, France, Japan, the United Kingdom and the United States from 1973 to the present, using a bottom-up approach relying on national data. Solís and Sheinbaum (2013) presented a disaggregation of the fuel consumption and its related $\mathrm{CO}_{2}$ emissions from passenger and freight road transport in Mexico. Zhou, Chung and Zhang (2013) studied $\mathrm{CO}_{2}$ emissions performance of the transport sector throughout China's 30 administrative regions using Data Envelopment Analysis (DEA) models with different return of scales. Kellner and Igl (2015) examined how the network carbon footprint of a real-world distribution system was affected by the logistics service provider network that was chosen to forward goods from production facilities to customers. Xu and Lin (2015) adopted provincial panel data from 2000 to 2012 and nonparametric additive regression models to examine the key influencing factors of $\mathrm{CO}_{2}$ emissions in the transport sector in China. 
We can find that many research achievements about $\mathrm{CO}_{2}$ emissions sprang up in different fields from above listed references. However, few scholars researched on carbon dioxide emission in logistics industry. A small quantity of scholars researched $\mathrm{CO}_{2}$ of logistics. For example, Zajac (2011) presented of the conception of counting the energy consumption of logistics warehouse systems. Tang, Wang, Yan and Hao (2014) examined the issue of cutting emissions by reducing shipment frequency within the framework of periodic inventory review system. Hammami, Nouira and Frein (2014) developed a deterministic optimization model that incorporates carbon emissions in a multi-echelon production-inventory model with lead time constraints. Logistics is a process of planning, implementing and controlling the efficient, costeffective flow and storage of raw materials, in-process inventory, finished goods and related information from point of origin to point of consumption for the purpose of conforming to customer requirement (Cooper, Lambert \& Pagh, 1997). Logistics has played an extremely important role in economic growth in China (Zhang \& Peng, 2009; Peng, 2011; Tan, 2003). On the other hand, it is a relatively energy-intensity industry, such as haul trucks, shipping and aircraft, which seriously rely on fossil fuel, and they emit greenhouse gas. Logistics activities accounted for roughly $5.5 \%$ share of global GHG emissions, around $90 \%$ of which came from transport, and the rest come from warehouses, load and unload (McKinnon, 2012).

There are close correlations between logistics and transportation. However, logistics presents some obvious differences with transportation. Transportation can be known as an important element of logistics. The generalized transportation includes passenger transport and freight transport, but logistics doesn't cover passenger transport.. The paper mainly contributes to reflect changes in carbon dioxide emission of China's logistics from a more extensive perspective, on the basis of transportation, storage, distribution, packaging, et al. It is different with the previous researches which were just based on transportation data, such as passenger transportation, or freight transportation, or the sum of the two. The main purpose of this paper is to: (1) estimate the $\mathrm{CO}_{2}$ emission in China's logistics sector; (2) analyze the causes for the change of $\mathrm{CO}_{2}$ emission; (3) identify the critical factors which mainly drive the change in $\mathrm{CO}_{2}$ emissions of logistics sector in China. The remainder of the paper is organized as follows. Section 2 mainly introduces the decomposition method of carbon dioxide emission and the source of data. Section 3 describes the statistical analysis of carbon dioxide emission in China's logistics industry, and presents the results of carbon dioxide emission decomposition. Section 4 presents the conclusions and some suggestions for sustainable logistics. 


\section{Methodology}

\subsection{Decomposition Methods}

There are several methods for decomposition analysis of energy consumption and $\mathrm{CO}_{2}$ emission. Especially, two famous decomposition methods, i.e. structural decomposition analysis (SDA) and index decomposition analysis (IDA), have been widely used, such as Wachsmann, Wood, Lenzen and Schaeffer (2009), Chang, Lewis and Lin (2008), Lise (2006), Akbostanc, Ipek-Tunç and Türüt-Aşık (2011). SDA was based on the input-output model, given to an analytical framework by Leontief (1966). Rose and Casler (1996) reviewed the development of SDA and its relationships to other methodologies, and presented the fundamental principles of alternative approaches. IDA was first used to study the impact of changes in product mix on industrial energy demand (Ang, Zhang \& Choi, 1998). Ang (2004) comprehensively compared the two popular index decomposition analysis methods, namely the Laspeyres index decompostition and the Divisia index decomposition, and recommended the log mean Divisia index (LMDI) method for general use due to its theoretical foundation, adaptability, ease of use and result interpretation, along with some other desirable properties in the context of decomposition analysis (Liu, Fan, Wu \& Wei, 2007). So we use the LMDI method to analyze the changes in $\mathrm{CO}_{2}$ emission of China's logistics industry in this paper.

According to the LMDI method firstly introduced by Ang, Zhang and Choi (1998), and the practical guide presented by Ang (2005), the changes in $\mathrm{CO}_{2}$ emissions from industry may be studied by quantifying the contributions from five different factors: activity effect, structure effect, intensity effect, fuel-mix effect and emission-factor effect. About $90 \% \mathrm{CO}_{2}$ emissions came from transport activity in logistics sector (McKinnon, 2012), so we further to divide the intensity effect into transport intensity effect and energy intensity effect. So we can research the changes in $\mathrm{CO}_{2}$ emission from logistics industry by quantifying the contributions from the following six different factors: logistics activity (measured by logistics added-value), transport intensity, transport mode shift, energy intensity, fuel mix and $\mathrm{CO}_{2}$ emission factors. The general index decomposition analysis (IDA) identity may be written as shown in Equation (1). The significance of symbols can be seen in Table 1.

$$
C=\sum_{i j} C_{i j}=\sum_{i j} Y \times \frac{Q}{Y} \times \frac{Q_{i}}{Q} \times \frac{E_{i}}{Q_{i}} \times \frac{E_{i j}}{E_{i}} \times \frac{C_{i j}}{E_{i j}}=\sum_{i j} Y \times T \times S_{i} \times I_{i} \times M_{i j} \times U_{i j}
$$




\begin{tabular}{|c|c|}
\hline Symbols & Description \\
\hline$i$ & Transport mode \\
\hline$j$ & Fuel type \\
\hline$C$ & Total carbon dioxide emission in study period \\
\hline$Y$ & Logistics activity, measured by logistics added-value \\
\hline$Q$ & Turnover volume of freight transport \\
\hline$Q_{i}$ & Consumption of fuel $j$ in $i$ th transport mode \\
\hline$E_{i j}$ & $T=Q / Y$, transport intensity \\
\hline$C_{i j}$ & $S_{i}=Q_{i} / Q_{,}$transport mode shift \\
\hline$T$ & $I_{i}=E_{i} / Q_{i}$, energy intensity \\
\hline$S_{i}$ & $M_{i j}=E_{i j} / E_{i}$ fuel mix \\
\hline$I_{i}$ & $U_{i j}=C_{i j} / E_{i j}$, carbon dioxide emission factor \\
\hline$M_{i j}$ & $C_{i j}$
\end{tabular}

Table 1 . Significance of symbols

The change of the aggregate carbon dioxide emission in logistics industry from the base year 0 to the target year $t$, denoted by Dtot or Etot, can be decomposed to six affect factors as follows: logistics activity effect (denoted by Dact or Eact), transport intensity effect (denoted by Dintt or Eintt), transport mode shift effect (denoted by Dstr or Estr), energy intensity effect (denoted by Dinte or Einte), fuel mix effect (denoted by Dmix or Emix), $\mathrm{CO}_{2}$ emission factors effect (denoted by Demf or Eemf), as shown in the form of Equation (2) and the additive form of Equation (3).

$$
\begin{gathered}
D_{\text {tot }}=C^{t} / C^{0}=D_{\text {act }} D_{\text {intt }} D_{\text {str }} D_{\text {inte }} D_{\text {mix }} D_{\text {emf }} \\
\Delta C_{\text {tot }}=C^{t}-C^{0}=\Delta C_{\text {act }}+\Delta C_{\text {intt }}+\Delta C_{\text {str }}+\Delta C_{\text {inte }}+\Delta C_{\text {mix }}+\Delta C_{\text {emf }}
\end{gathered}
$$

According to the multiplicative and additive decomposition method recommended by Ang (2005), each term of Equations (2) and (3) can be calculated applying the LMDI method, which were shown in Appendix A-Table A1.

\subsection{Management of Data}

There are no compiled data of logistics industry in the related Chinese yearbooks, but we can find a statistical index in China Statistical Yearbooks and China Transport Yearbooks, which included the related statistical data about transport, storage and communications, we can regard the index as a proximate proxy of logistics industry (Liu \& Li, 2007; Zhang \& Yu, 2012). In this paper, we use the "top-down" method to calculate $\mathrm{CO}_{2}$ emissions in logistics industry, which estimates $\mathrm{CO}_{2}$ emissions on basis of the total amount of fuel consumption. $\mathrm{CO}_{2}$ emissions of the ith transport mode in year $t$ can be calculated by multiplying fuel consumption 
of one fuel type used in the $i$ th transport mode and the $\mathrm{CO}_{2}$ emission factor of the fuel type $j$. If different fuels are used in one transport mode, we should summarize the $\mathrm{CO}_{2}$ emission of different fuel types in the mode (Loo \& Li, 2012). For example, the fuel types include coal, diesel and electricity in railway transport mode. The main energy fuels are gasoline and diesel in highway transport mode, and they are jet kerosene and aviation gasoline in the aviation transport. For water transport, the primary fuel is diesel. The energy consumption data of different freight transport modes can be obtained and calculated from China Statistical Yearbook, Yearbook of China Transportation and Communication, Compile of China Aviation Statistics in different stages. Emission factor data came from IPCC Guidelines for National Greenhouse Gas Inventories (2006), as shown in Table 2.

\begin{tabular}{|c|c|c|c|}
\hline Fuel type & $\begin{array}{c}\mathbf{C O}_{2} \text { emission factor } \\
(\mathbf{k g} / \mathbf{T} \mathbf{J})\end{array}$ & $\begin{array}{c}\text { Net calorific value } \\
(\mathbf{T J} / \mathbf{G g})\end{array}$ & $\begin{array}{c}\text { Emission factor } \\
(\mathbf{k g ~ C O} / \text { ton fuel) }\end{array}$ \\
\hline Coal & 96,100 & 18.9 & 1816.29 \\
\hline Jet kerosene & 71,500 & 44.1 & 3153.15 \\
\hline Aviation gasoline & 70,000 & 44.3 & 3101.00 \\
\hline Motor gasoline & 69,300 & 44.3 & 3069.99 \\
\hline Diesel & 74,100 & 43.0 & 3186.30 \\
\hline
\end{tabular}

Table 2. $\mathrm{CO}_{2}$ emission factor by type of transport fuel

Carbon emission coefficients of fuels have changed with an updating in level of fuels. Because of the relatively short study period, these changes of the emission coefficients can be ignored when we analyze the macro changes in $\mathrm{CO}_{2}$ emission, we assume that the $\mathrm{CO}_{2}$ coefficients of coal, kerosene, gasoline and diesel are constant. However, $\mathrm{CO}_{2}$ coefficient of electricity is continuously changing, due to the fuel mix used and technological improvements in the generation of electricity. We use the net standard coal consumption rate $(\mathrm{g} / \mathrm{kw} . \mathrm{h})$ to describe the energy consumptions which were used to generate one kilowatt hour. We can obtain the data from China Energy Statistical Yearbook. So, the $\mathrm{CO}_{2}$ emission coefficient is restricted to the impact of changes in electricity emission rate, which is calculated on basis of the individual fuels used in power generation (Liu, Fan, Wu \& Wei, 2007; Wang, Zhang \& Zhou, 2011).

\section{Results and Discussion}

\subsection{Total $\mathrm{CO}_{2}$ Emission in Chinese Logistics Industry}

Figure 2 presents the trend of total $\mathrm{CO}_{2}$ emission in China's logistics industry from 1980 to 2010. It's obvious that the $\mathrm{CO}_{2}$ emission has a continuously raising trend in the study period. It has increased by 21.5 times from 45.1 million tons $\mathrm{CO}_{2}$ in 1980 to 1014.1 million tons $\mathrm{CO}_{2}$ in 2010 , with the average growth rates was $11.7 \%$, which accounted for $12.2 \%$ share of total $\mathrm{CO}_{2}$ 
emission of China. The result showed that logistics industry has gradually become one of the leading source of $\mathrm{CO}_{2}$ emission. The aggregate $\mathrm{CO}_{2}$ emission in logistics has close relationship with economic growth. Economic growth caused the increasing demand for logistics service, then, logistics activities increased the energy consumption and thus produced more $\mathrm{CO}_{2}$ emission, especially the transport, which consumed numerous fossil fuels. We can see that the changing trend was a gentle up-incline before 2007, and suddenly became upward sharply after 2007 in the Figure 2. Especially in 2007 and 2008, the change of $\mathrm{CO}_{2}$ emission were remarkable, with the growth rate of $63.5 \%$ and $51.1 \%$, respectively, which resulted from Chinese government's numerous invests on infrastructure for pursuing the continuous economic growth.

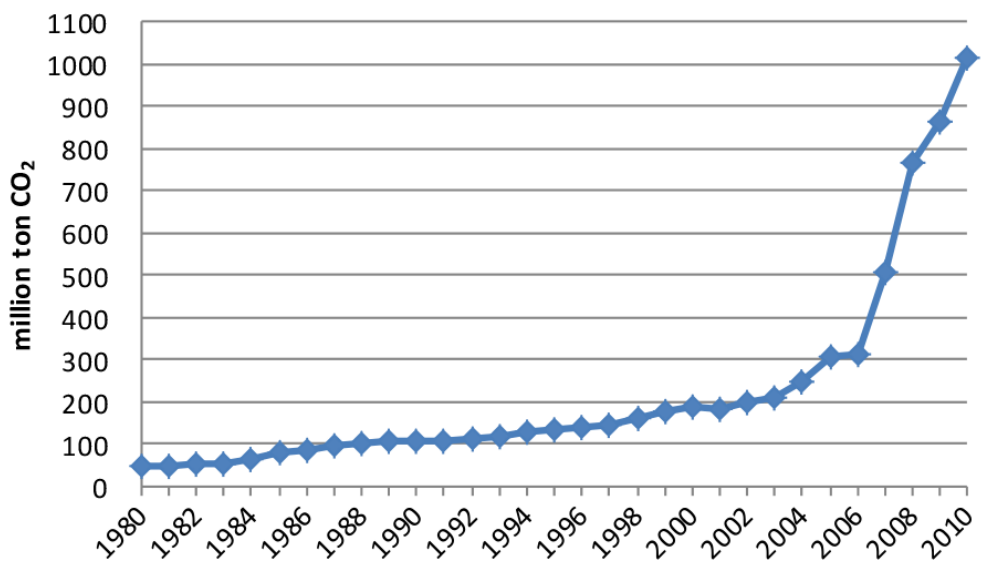

Figure 2. Total $\mathrm{CO}_{2}$ emission in Chinese logistics industry

We further to analyze the distribution of annual $\mathrm{CO}_{2}$ emission according to the transport modes to understand the composition of $\mathrm{CO}_{2}$ emission in logistics industry well. Figure 3 shows the percentages of $\mathrm{CO}_{2}$ emission in different transport modes in each year from 1980 to 2010 . From Figure 3, we can conclude that the highway transport was a main contributor to $\mathrm{CO}_{2}$ emission, it accounted for $76.8 \%$ (or 778.47 million tons $\mathrm{CO}_{2}$ ) share of total $\mathrm{CO}_{2}$ emission in 2010. The reasons were that the demand for highway transport was increasing in recent years due to its convenience and flexibility, and the highway transport mainly relied on the fossil energy. Next to highway transport, waterway transport ranked the second, which accounted for $18.1 \%$ (or 183.37 million tons $\mathrm{CO}_{2}$ ) of total $\mathrm{CO}_{2}$ emission in 2010 , and it is noticed that the statistical data of waterway transport included ocean transport in China Statistical Yearbook. Railway transport ranked the third with reduction from $32.3 \%$ share in 1980 to $2.53 \%$ in 2010 . The main reason is the replacement of the coal-fired steam locomotives with diesel/electric locomotives (Wang, Zhang \& Zhou, 2011). The freight aviation transport had small proportion and ranked the fourth, which only accounted for $1.69 \%$ share of total $\mathrm{CO}_{2}$ emission, however, its growth rate was the most obvious, it increased by 89.4 times, from 0.19 million tons $\mathrm{CO}_{2}$ in 1980 to 17.12 million tons $\mathrm{CO}_{2}$ in 2010 . It may be explained by the changing of production 
mode, for example, the Just-In-Time (JIT) requests to reduce the inventory as far as possible, which made promptness of delivery become an important factor. In order to satisfy customer's requirements, more and more suppliers choose the aviation transport due to its quick speed.

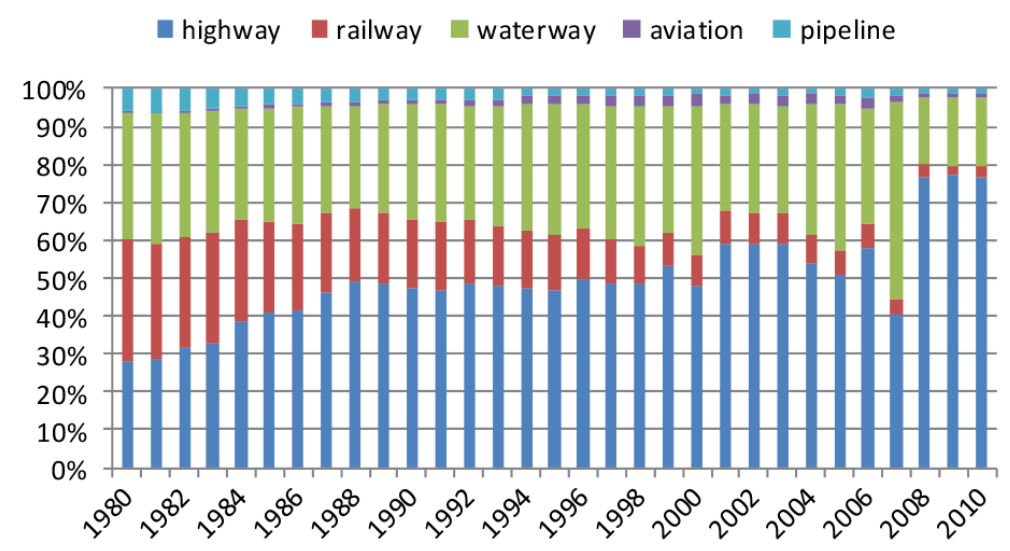

Figure 3. Percentage of $\mathrm{CO}_{2}$ emission in different transport modes

\subsection{Intensity of $\mathrm{CO}_{2}$ Emission in Logistics Industry}

The $\mathrm{CO}_{2}$ emission intensity of logistics can be defined as the $\mathrm{CO}_{2}$ emission per unit of logistics output, which can be measured by the added value of logistics and the turnover volume of freight transport. So we analyze the $\mathrm{CO}_{2}$ emission from two aspects, i.e. $\mathrm{CO}_{2}$ emission per added value of logistics (million tons $\mathrm{CO}_{2}$ per billion Yuan) and $\mathrm{CO}_{2}$ emission per turnover volume of each transport mode (million tons $\mathrm{CO}_{2}$ per billion km-tons). As shown in Figure 4, it presents the changing trend of $\mathrm{CO}_{2}$ emission of logistics in China. In general, the $\mathrm{CO}_{2}$ emission of logistics tends to flat in the period of 1980-2006. However, there were dramatic changes in intensity of $\mathrm{CO}_{2}$ emission between 2006 and 2010, with increasing from 3.06 million tons $\mathrm{CO}_{2}$ per billion Yuan in 2006 to 8.74 million tons $\mathrm{CO}_{2}$ per billion Yuan in 2010 (constant price in 1980). There are some reasons for the obvious changes in intensity of $\mathrm{CO}_{2}$ emission, for example, Chinese government invested vast funds in infrastructure for economic growth from 2006 to 2010, which boosted the increase of logistics demand rapidly, and it exceeded the technological updating speed for energy conservation and emission reduction. On the other hand, the transport mode obviously changed from lower energy consumption mode to higher energy consumption mode in 2006-2010. The turnover volume ratio of railways to total turnover volume of freight transport decreased from $24.71 \%$ in 2006 to $19.49 \%$ in 2010; the ratio of highway transport increased from $10.98 \%$ in 2006 to $30.59 \%$, especially in 2008, the turnover volume of highway transport increased by 1.89 times than last year, from 1135.5 billion ton-km to 3286.8 billion ton-km. So the economic growth and energy mix are important factors for the changing in intensity of $\mathrm{CO}_{2}$ emission. 


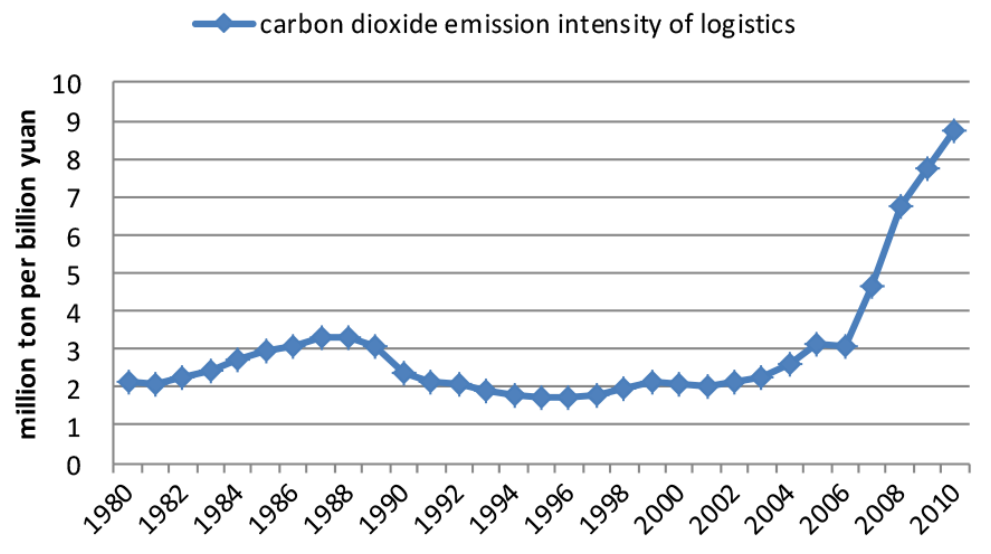

Figure 4. $\mathrm{CO}_{2}$ emission intensity of logistic industry

As shown in Figure 5, we present the chart of changes in the intensity of $\mathrm{CO}_{2}$ emission according to transport mode, for comparing the $\mathrm{CO}_{2}$ emission difference of different transport modes. It is easy to find out that the railway transport owns the lowest $\mathrm{CO}_{2}$ emission intensity and presents a declining trend, it was because the economies of scale of railway transport increased and steam locomotive was replaced by electric locomotives. The aviation transport has the highest $\mathrm{CO}_{2}$ emission intensity, due to high energy intensity and less loading capacity, but it is decreasing in recent years, which attributed to the improvement of aviation fuel quality. Next to aviation transport, the $\mathrm{CO}_{2}$ emission intensity of highway transport was the second and presented an increasing trend in recent years. The diesel and gasoline are important fuel energy of highway transport, which are the main source of $\mathrm{CO}_{2}$. The sharp increasing of freight transport volume resulted in the increasing of transport intensity, which caused that the increasing of carbon emission exceeded the increasing of logistics output, on the other hand, the continuous use of transportation facility would make the vehicle condition worse, which can increase the emission intensity.

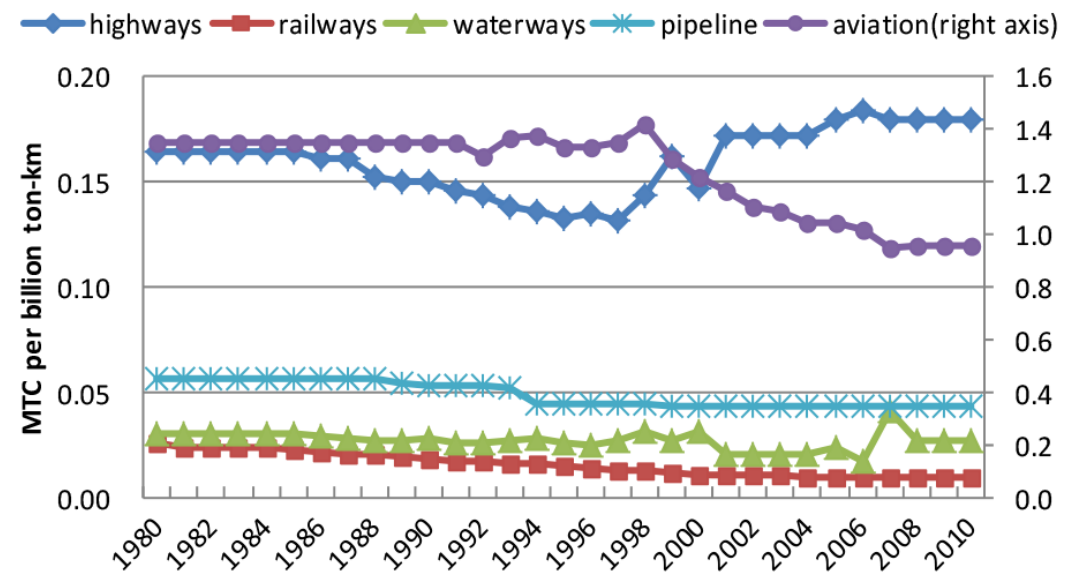

Figure 5. $\mathrm{CO}_{2}$ emission intensity in different transport modes 


\subsection{Decomposition Results of $\mathrm{CO}_{2}$ Emission from Chinese Logistics Industry}

In this paper, we used logarithmic mean Divisia index (LMDI) method to explore the multiplicative and additive decomposition of $\mathrm{CO}_{2}$ emission in China's logistics industry. The decomposition results are based on Equations (2) and (3) and the LMDI formula in Appendix A-Table $A 1$, as shown in Table 3 and Table 4. Figures 6-7 showed the radar charts for multiplicative decomposition and the bar charts for additive decomposition of $\mathrm{CO}_{2}$ emission in logistics industry by using the numerical results presented in Tables 3-4, respectively.

\begin{tabular}{|c|c|c|c|c|c|c|c|}
\hline & Dtot & Dact & Dintt & Dsrt & Dinte & Dmix & Demf \\
\hline $1980-1990$ & 2.359 & 2.083 & 1.025 & 1.260 & 0.870 & 1.009 & 0.999 \\
\hline $1990-2000$ & 1.756 & 1.903 & 0.868 & 1.093 & 0.955 & 1.020 & 0.998 \\
\hline $2000-2005$ & 1.642 & 1.095 & 1.614 & 0.929 & 0.962 & 1.041 & 0.999 \\
\hline $2005-2010$ & 3.308 & 1.182 & 1.468 & 1.832 & 1.021 & 1.022 & 0.998 \\
\hline $1980-2010$ & 22.495 & 3.314 & 1.729 & 2.005 & 0.947 & 2.076 & 0.997 \\
\hline
\end{tabular}

Table 3. Multiplication decomposition of $\mathrm{CO}_{2}$ emission in logistics industry

\begin{tabular}{|c|c|c|c|c|c|c|c|}
\hline & $\Delta$ Ctot & $\Delta$ Cact & $\Delta$ Cintt & $\Delta$ Cstr & $\Delta$ Cinte & $\Delta$ Cmix & $\Delta$ Cemf \\
\hline $1980-1990$ & 61.270 & 52.385 & 1.770 & 16.489 & -9.949 & 0.614 & -0.039 \\
\hline $1990-2000$ & 80.352 & 91.902 & -20.154 & 12.649 & -6.637 & 2.837 & -0.245 \\
\hline $2000-2005$ & 119.834 & 21.976 & 115.751 & -17.786 & -9.451 & 9.676 & -0.331 \\
\hline $2005-2010$ & 707.602 & 98.889 & 227.156 & 357.898 & 12.130 & 12.635 & -1.108 \\
\hline $1980-2010$ & 969.058 & 372.969 & 170.351 & 216.454 & -17.053 & 227.328 & -0.992 \\
\hline
\end{tabular}

Table 4. Additive decomposition of $\mathrm{CO}_{2}$ emission in logistics industry

\subsubsection{Total Change in Carbon Dioxide Emission Between 1980 and 2010}

Figures 6-7 describe the results of the multiplicative and additive decomposition analyses of logistics industry in China. According to the analysis, we can conclude that the total $\mathrm{CO}_{2}$ emission had changed greatly, with the accumulated increasing of 969.1 million tons $\mathrm{CO}_{2}$ emission from 1980 to 2010, and logistics activity, transport intensity, transport mode shift and fuel mix are important factors in increasing the $\mathrm{CO}_{2}$ emission of logistics sector in China. However, the energy intensity and the factors that influenced $\mathrm{CO}_{2}$ emission contributed to the reduction of $\mathrm{CO}_{2}$ emission in overall research period, which factors had multiplicative indexes less than one and additive indexes below zero, as shown in Figure 6. 


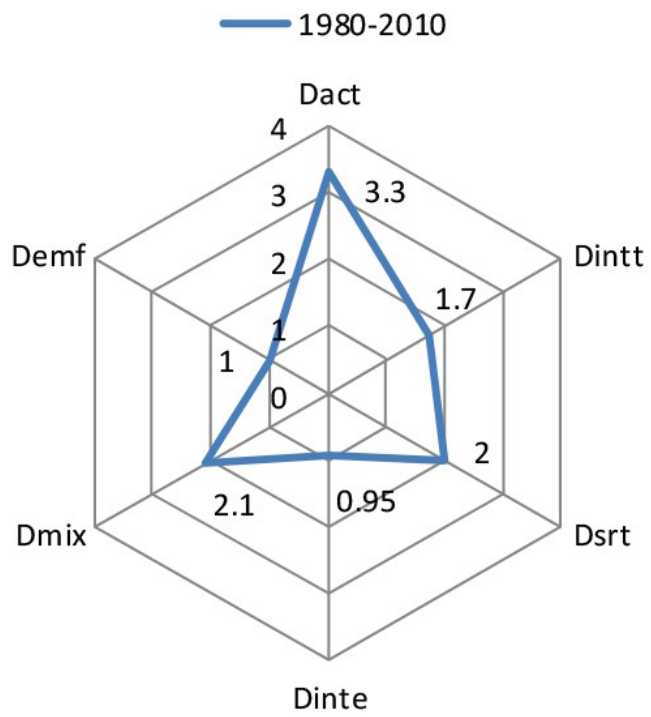

Figure 6. Radar chart for $\mathrm{CO}_{2}$ emission decomposition in 1980-2010

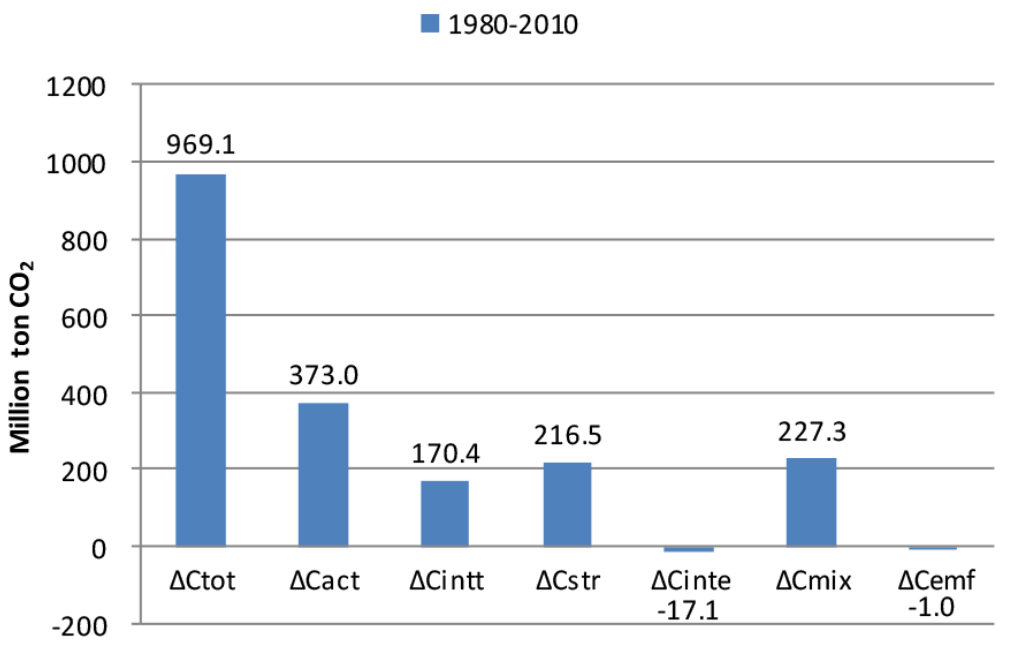

Figure 7. Bar chart for $\mathrm{CO}_{2}$ emission decomposition in 1980-2010

Logistics activity is the most important factor contributing to the increase of $\mathrm{CO}_{2}$ emission in logistics industry, which increased 373 million tons $\mathrm{CO}_{2}$ emission, with $38.5 \%$ share of total $\mathrm{CO}_{2}$ emission change. The main reason was that the rapid economic growth boosted the demand for logistics service, with the increasing of freight turnover volume from 1202.7 billion kilometer-tons in 1980 to 14183.7 billion kilometer-tons in 2010, thus indirectly resulting in the increase of energy consumption and $\mathrm{CO}_{2}$ emission. China's economy has continuously developed in recent thirty years since reform and opening-up. However, China is still at the primary stage of motorization and the economic growth is at the cost of consuming a great deal of natural resource. In addition, the integrated logistics system cannot operate efficiently because of the outdated logistics technology and management method, which resulted in low energy efficiency and high carbon emission intensity. 
Next, fuel mix is another important factor to the increase of $\mathrm{CO}_{2}$ emission in logistics sector, which caused the accumulated increasing of 227.3 million tons carbon emission, with $23.5 \%$ share of total $\mathrm{CO}_{2}$ emission change. Transport mode shift ranked the third, with the increasing of 216.5 million tons carbon emission and $22.3 \%$ share. In fact, there was a tight relationship between fuel mix and transport mode shift, transport mode determined the fuel type. The decomposition results have shown that the transport modes and energy structure are unreasonable in China, and the petroleum is still the primary energy source in logistics activities at present. Transport intensity ranked the fourth, with the increase of 170.4 million tons carbon emission and $17.6 \%$ share. Because of the development of global economy, change of production and management mode, the transport distance increased and the transport intensity increased from $56.4 \mathrm{~km}$-tons per Yuan in 1980 to $122.2 \mathrm{~km}$-tons per Yuan in 2010, which caused the increase of energy consumption and emission.

The decomposition result showed that energy intensity caused the $\mathrm{CO}_{2}$ emission to reduce by 17.1 million tons between 1980 and 2010, and it accounted for $1.8 \%$ share of total change in absolute value. It may attribute to the effective strategies which aimed at improving energy efficiency, such as introducing advanced logistics technologies, updating logistics facilities and equipment, improving fuel quality, and so on. In recent years, Chinese government is making efforts to save energy and reduce emission in logistics sector. The $\mathrm{CO}_{2}$ emission factor has small effect on the change in $\mathrm{CO}_{2}$ emission in logistics industry, with the reduction of only 1 million tons carbon emission. It was because that we assumed the carbon emission coefficients of coal, diesel, gasoline and kerosene were constant. The carbon emission coefficient of electricity was calculated on basis of the individual fossil fuels used in power generation.

\subsubsection{Change of Carbon Dioxide Emission in Different Periods}

We divided the study period into multi-stages in order to examine the factors that caused the change in $\mathrm{CO}_{2}$ emission of logistics well. Chinese administration departments take five years as a plan cycle when they make macro policies. We suppose that there are no obvious differences in two continuous five-year plans. So we divide the research period into three sub-stages, i.e. 1980-1990, 1990-2000 and 2000-2010. Additionally, taking account of rapid economic growth and policy adjustment in recent ten years, we further divided the period 2000-2010 into 2000-2005 and 2005-2010. Figures 8-9 showed the radar charts for multiplicative decomposition and the bar charts for additive decomposition of $\mathrm{CO}_{2}$ emission in logistics industry in different sub-stages, respectively. 


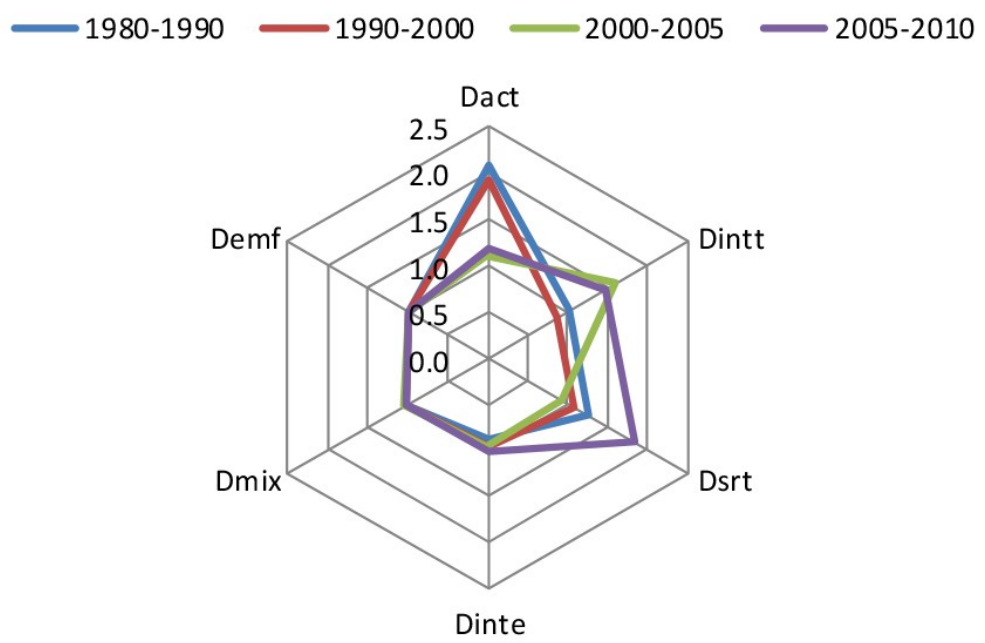

Figure 8. Radar chart for $\mathrm{CO}_{2}$ emission decomposition in multi-stages

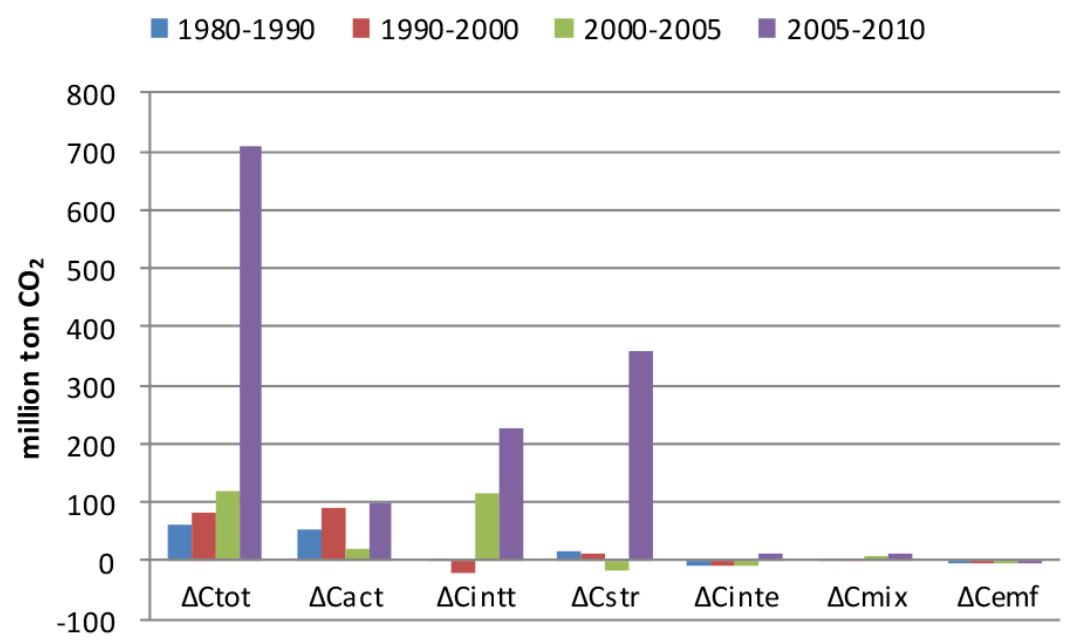

Figure 9. Bar chart for $\mathrm{CO}_{2}$ emission decomposition in multi-stages

The change in $\mathrm{CO}_{2}$ emission in different sub-stages (in turn, 1980-1990, 1990-2000, 20002010 , accounted for $6.3 \%, 8.3 \%, 85.4 \%$ share of the total $\mathrm{CO}_{2}$ emission change, respectively, with the increasing of $61.27,80.35,827.43$ million tons carbon emission in the study period. The $\mathrm{CO}_{2}$ emission of China's logistic industry had greatly increased in the period of 2000-2010. Especially, in the stage of $2005-2010$, it accounted for $73 \%$ share of total $\mathrm{CO}_{2}$ emission in research period, with the increasing of 707.6 million tons carbon emission. Global economy was in recession in that time, Chinese government endeavored to pull domestic demand by investing plenty of money in public service and infrastructure to deal with world financial crisis in 2008. China's GDP ranked the second place, which is next to America and exceeded Japan in the world in 2010. As previously mentioned, economic growth would make the demand for logistics service increase, and it enhanced the energy consumption and $\mathrm{CO}_{2}$ emission. 
From Figures 8-9, we can conclude that the changes in $\mathrm{CO}_{2}$ emission and the influence factors have extreme similarities between the stages of 1980-1990 and 1990-2000. For example, logistics activity was the leading factor that caused the increase of $\mathrm{CO}_{2}$ emission, with $85.5 \%$ and $114.4 \%$ share of the total change in the two periods, respectively; the energy intensity and the emission factor had positive roles in reducing the $\mathrm{CO}_{2}$ emission due to the updating and innovation of logistics technologies and logistics equipment. However, the critical factors to changing in carbon emission were transformed in recent ten years. For example, logistics activity, transport intensity and fuel mix had adverse effect on the change in carbon emission from 2000 to 2005; herein, transport intensity was the first primary contributor to the increase of carbon emission. Transport structure, energy intensity and emission factor had positive role in decreasing carbon emission. From 2005 to 2010, all decomposition factors leaded to the increase of $\mathrm{CO}_{2}$ emission, except for emission factor. Transport structure played the most important role in increasing $\mathrm{CO}_{2}$ emission with 358 million tons $\mathrm{CO}_{2}$ emission, which accounted for $50.6 \%$ share of total $\mathrm{CO}_{2}$ emission. The effect resulted from the change of transport model from lower energy consumption model such as railway transport to higher energy consumption model such as highway and aviation transport. Transport mode shift mainly depended on customer's demand for transportation service, such as cost, security, convenience, promptness, flexibility, and so on.

\section{Conclusions and Policy Implications}

\subsection{Conclusions}

Carbon dioxide emission has a tight link with economic growth and energy consumption. As an emerging and important industry in China, the logistics industry is promoting economic growth; on the other hand, it consumed a great deal of energy and emitted plenty of $\mathrm{CO}_{2}$, and it was the main reason for global warming. In order to examine the change in $\mathrm{CO}_{2}$ emission of China's logistics industry, we firstly calculated the carbon dioxide emission of logistics industry in the period of 1980-2010; and further analyzed the factors that influenced the changes in $\mathrm{CO}_{2}$ emission of logistics industry by using logarithmic mean Divisia index (LMDI) method. We can draw some conclusions from the present study as follows:

1. Carbon dioxide emission in China's logistics industry has a continually rising trend in the study period. It has increased by 21.5 times, from 45.1 million tons $\mathrm{CO}_{2}$ in 1980 to 1014.1 million tons $\mathrm{CO}_{2}$ in 2010 , with the average annual growth rate of $11.7 \%$, which accounted for $12.2 \%$ share of total $\mathrm{CO}_{2}$ emission of China.

2. The highway transport is the main contributor to carbon dioxide emission in logistics activities, which accounted for $76.8 \%$ (or 778.47 million tons $\mathrm{CO}_{2}$ ) share of total carbon dioxide emission in 2010. The waterway transport ranked the second, which accounted 
for $18.1 \%$ (or 183.37 million tons $\mathrm{CO}_{2}$ ) of total carbon emission; railway, aviation and pipeline accounted for $2.5 \%, 1.7 \%$ and $0.9 \%$, respectively.

3. According to the results of decomposition, logistics activity, transport mode shift, transport intensity and fuel mix are critical effect factors to the increase of change in $\mathrm{CO}_{2}$ emission, however, the energy intensity and $\mathrm{CO}_{2}$ emission factors were contributing to the reduction of carbon dioxide emission in China's logistics industry in overall study period. Therein, logistics activity is the most important factor contributing to the increase of $\mathrm{CO}_{2}$ emission in logistics during the period of 1980-2010, which increased 373 million tons carbon emission, with $38.5 \%$ share of total $\mathrm{CO}_{2}$ emission change.

4. The critical effect factor caused the change in $\mathrm{CO}_{2}$ emission in logistics sector would vary with the change of external environment factors, such as economy level, logistics technology and equipment, energy price, labor cost, production and management mode, and so on.

\subsection{Policy Implications}

Facing the rapid growth in demand for logistics services due to economic growth, it's difficult to decrease total $\mathrm{CO}_{2}$ emission in logistics industry, because there are tight relations between economic growth, logistics demand, energy growth and carbon emission. However, we can take some strategies to improve energy efficiency and reduce $\mathrm{CO}_{2}$ emission per unit of energy consumption, which can offset the increase of total $\mathrm{CO}_{2}$ emission, such as: (1) Optimize social logistics system and update logistics facility and equipment. Logistics is an extremely complex economy activity. It is significant to optimize the social logistics system for energy conservation and emission reduction. Nevertheless, logistics has been paid attention in recent years, and the current logistics system is unreasonable in China, such as unscientific layout of logistics network, underdeveloped traffic condition, outdated warehouse, and so on. The administration departments should further to optimize social logistics system by relocating and constructing gather and distribution centers, junction stations, and building modern warehouse for improving logistics operation efficiency, reducing energy consumption and emission. (2) Encourage transport mode to shift from high emission to low carbon mode. The research result showed that the transport mode has critical effect on the change of $\mathrm{CO}_{2}$ emission. Railway transport and waterway transport have low energy intensity and strong transport capacity; however, due to the flexibility and convenience of highway transport and aviation transport's promptness, the share of freight turnover volumes present an increasing trend in recent years in China. Policy makers can encourage people to choose lower energy consumption transport by making transport pricing policy. (3) Introduce advanced information communication technology. Information communication technology (ICT) helps operators to make efficient route plan and schedule, vehicle loading, driving time and travel distance, and it can avoid 
traffic congestion and reduce energy consumption and emission (Liao et al., 2011). ICT was generally utilized in truck transport in developed countries; however, few operators use it in China. So it is necessary to introduce advanced information communication technology. (4) Increase investment on designing high fuel efficiency and low emission engine. Efficient engine design and fuel economy standard play a great role in cutting fuel demand, which can improve trucks fuel economy (Schipper, 2009). However, because of the limited technology resource, China's transport carrier emission standard is still lower than international emission standard. Scientific and technological administrations should increase investment and organize R\&D team to design high fuel efficiency and low emission engine. (5) Improve electricity generation and fuel refining technology. The development of energy technology has a little positive effect in decreasing the energy consumption and carbon emission in recent years in China, but it's very limited. Energy and environment administration division should make effort to improve the electricity generation and fuel refining technology for reducing the carbon coefficients. For example, the power stations can adopt new energy technologies, such as nuclear power, wind power, solar power and biomass power to generate electricity. In addition, high quality fuel can release more energy and less emission, and the petroleum companies should explore and introduce new fuel refining technology to improve the purity of fuel oil.

\section{Acknowledgments}

The authors gratefully acknowledge the National Social Science Fund of China (NSSF) under Grants No.14BGL100, and the financial support from the National Natural Science Foundation of China (NSFC) under Grants No.71301182, and the Chongqing Science \& Technology Commission under Grants No.cstc2014jccxB60001, and from Chongqing Liangjiang Scholar Planning.

\section{References}

Acaravcia, A., \& Ozturk, I. (2010). On the relationship between energy consumption, $\mathrm{CO}_{2}$ emissions and economic growth in Europe. Energy, 35(12), 5412-5420.

http://dx.doi.org/10.1016/j.energy.2010.07.009

Akbostancl, E., Ipek-Tunç, G., \& Türüt-Aşık, S. (2011). $\mathrm{CO}_{2}$ emissions of Turkish manufacturing industry: A decomposition analysis. Applied Energy, 88(6), 2273-2278.

http://dx.doi.org/10.1016/j.apenergy.2010.12.076

Ang, B.W. (2004). Decomposition analysis for policymaking in energy in energy: which is the preferred method? Energy Policy, 32(9), 1131-1139. http://dx.doi.org/10.1016/S0301-4215(03)00076-4 
Ang, B.W. (2005). The LMDI approach to decomposition analysis: a practical guide. Energy Policy, 33, 867-871. http://dx.doi.org/10.1016/j.enpol.2003.10.010

Ang, B.W., Zhang, F., \& Choi, K.H. (1998). Factorizing changes in energy and environmental indicators through decomposition. Energy, 23(6), 489-495. http://dx.doi.org/10.1016/S03605442(98)00016-4

Azadeh, A., Khakestani, M., \& Saberi, M. (2009). A flexible fuzzy regression algorithm for forecasting oil consumption estimation. Energy Policy, 37(12), 5567-5579.

http://dx.doi.org/10.1016/j.enpol.2009.08.017

Chapman, L. (2007). Transport and climate change: a review. Journal of Transport Geography, 15, 354-367. http://dx.doi.org/10.1016/j.jtrangeo.2006.11.008

Chang, Y.F., Lewis, C., \& Lin, S.J. (2008). Comprehensive evaluation of industrial $\mathrm{CO}_{2}$ emission (1989-2004) in Taiwan by input-output structural decomposition. Energy Policy, 36(7), 2471-2480. http://dx.doi.org/10.1016/j.enpol.2008.01.043

Cooper, M.C., Lambert, D.M., \& Pagh, J.D. (1997). Supply Chain Management: More Than a New Name for Logistics. International Journal of Logistics Management, 8(1), 1-14. http://dx.doi.org/10.1108/09574099710805556

Fatumata, K., \& Lee, S. (2009). Trends in truck freight energy use and carbon emissions in selected OECD countries from 1973 to 2005. Energy Policy, 37(10), 3743-3751. http://dx.doi.org/10.1016/j.enpol.2009.07.029

Ghosh, S. (2010). Examining carbon emissions economic growth nexus for India: A multivariate cointegration approach. Energy Policy, 38(6), 3008-3014.

http://dx.doi.org/10.1016/j.enpol.2010.01.040

Halicioglu, F. (2009). An econometric study of $\mathrm{CO}_{2}$ emissions, energy consumption, income and foreign trade in Turkey. Energy Policy, 37(3), 1156-1164.

http://dx.doi.org/10.1016/j.enpol.2008.11.012

Hammami, R., Nouira, I., \& Frein, Y. (2014). Carbon emissions in a multi-echelon production-inventory model with lead time constraints. International Journal of Production Economics, 164(6), 292-307.

Hammond, G.P., \& Norman, J.B. (2012). Decomposition analysis of energy-related carbon emissions from UK manufacturing. Energy, 41(1), 220-227.

http://dx.doi.org/10.1016/j.energy.2011.06.035

Kellner, F., \& Igl, J. (2015). Greenhouse gas reduction in transport: analyzing the carbon dioxide performance of different freight forwarder networks. Journal of Cleaner Production, 99, 177-191. http://dx.doi.org/10.1016/j.jclepro.2015.03.026

Ipek-Tunç, G., Türüt-Aşık, S., \& Akbostanci, E. (2009). A decomposition analysis of $\mathrm{CO}_{2}$ emissions from energy use: Turkish case. Energy policy, 37, 3689-3699.

http://dx.doi.org/10.1016/j.enpol.2009.06.019 
Leontief, W. (1966). Input-output analysis foundations and extensions. New York: Oxford University Press.

Liao, C.H., Lu, C.S., \& Tseng, P.H. (2011). Carbon dioxide emissions and inland container transport in Taiwan. Journal of Transport Geography, 19(4), 722-728.

http://dx.doi.org/10.1016/j.jtrangeo.2010.08.013

Lise, W. (2006). Decomposition of $\mathrm{CO}_{2}$ emissions over 1980-2003 in Turkey. Energy Policy, 34(14), 1841-1852. http://dx.doi.org/10.1016/j.enpol.2004.12.021

Liu, L.C., Fan, Y., Wu, G., \& Wei, Y.M. (2007). Using LMDI method to analyze the change of China's industrial $\mathrm{CO}_{2}$ emissions from final fuel use: An empirical analysis. Energy Policy, 35(11), 5892-5900. http://dx.doi.org/10.1016/j.enpol.2007.07.010

Liu, N., \& Li, Y. (2007). Interaction between Logistics Development and Economic Growth in China. Journal of Industrial Engineer and Management, 21(1), 151-154.

Loo, P.Y., \& Li, L. (2012). Carbon dioxide emission from passenger transport in China since 1949: implications for developing sustainable transport. Energy policy, 50, 464-476. http://dx.doi.org/10.1016/j.enpol.2012.07.044

Menyah, K., \& Wolde-Rufael, Y. (2010). Energy consumption, pollutant emissions and economic growth in South Africa. Energy Economics, 32(6), 1374-1382.

http://dx.doi.org/10.1016/j.eneco.2010.08.002

McKinnon, A.C. (2012). Reducing energy consumption and emissions in the logistics sector. Energy, Transport, \& the Environment, 521-537. http://dx.doi.org/10.1007/978-1-4471-2717-8_29

Olsthoorn, X. (2001). Carbon dioxide emissions from international aviation: 1950-2050. Journal of Air Transport Management, 7(2), 87-93. http://dx.doi.org/10.1016/S0969-6997(00)00031-4

Pao, H.T., Yu, H.C., \& Yang, Y.H. (2011). Modeling the $\mathrm{CO}_{2}$ emissions, energy use, and economic growth in Russia. Energy, 36(8), 5094-5100.

http://dx.doi.org/10.1016/j.energy.2011.06.004

Peng J. (2011). Analysis of Logistics Capability' Support to Regional Economic Growth. Forecasting, 30(5), 59-63,75.

Rose, A., \& Casler, S. (1996). Input-output structural decomposition analysis: a critical appraisal. Economic Systems Research, 8, 33-62. http://dx.doi.org/10.1080/09535319600000003

Schmitz, A., Kamiński, J, Scalet, B.M., \& Soria, A. (2011). Energy consumption and $\mathrm{CO}_{2}$ emissions of the European glass industry. Energy Policy, 39(1), 142-155.

http://dx.doi.org/10.1016/j.enpol.2010.09.022

Schipper, L. (2009). Fuel economy, vehicle use and other factors affecting $\mathrm{CO}_{2}$ emissions from transport. Energy Policy, 37, 3711-3713. http://dx.doi.org/10.1016/j.enpol.2009.07.028

Sheinbaum, C., Ozawa, L., \& Castillo, D. (2010). Using logarithmic mean Divisia index to analyze changes in energy use and carbon dioxide emissions in Mexico's iron and steel industry. Energy Economics, 32(6), 1337-1344. http://dx.doi.org/10.1016/j.eneco.2010.02.011 
Solís, J.C., \& Sheinbaum, C. (2013). Energy consumption and greenhouse gas emission trends in Mexican road transport. Energy for Sustainable Development, 17(3), 280-287. http://dx.doi.org/10.1016/j.esd.2012.12.001

Steenhof, P., Woudsma, C., \& Sparling, E. (2006). Greenhouse gas emissions and the surface transport of freight in Canada. Transportation Research Part D: Transport and Environment, 11, 369-376. http://dx.doi.org/10.1016/j.trd.2006.07.003

Tan, Q.M. (2003). Research on the Contribution of Logistics Ability to Regional Economy. Modern economic research, 8, 22-24.

Tang, S., Wang, W., Yan, H., \& Hao, G. (2014). Low carbon logistics: Reducing shipment frequency to cut carbon emissions. International Journal of Production Economics, 164(7), 339-350.

U.S. Energy Information Administration (EIA) (2015). Total primary energy consumption. Available at: http://www.eia.gov/countries/analysisbriefs/China/china.pdf

Wachsmann, U., Wood R, Lenzen M, \& Schaeffer R. (2009). Structural decomposition of energy use in Brazil from 1970 to 1996. Applied Energy, 86(4), 578-587.

http://dx.doi.org/10.1016/j.apenergy.2008.08.003

Wang, S.S., Zhou, D.Q., \& Zhou, P. (2011). $\mathrm{CO}_{2}$ emissions, energy consumption and economic growth in China: A panel data analysis. Energy Policy, 39(9), 4870-4875.

http://dx.doi.org/10.1016/j.enpol.2011.06.032

Wang, W.W., Zhang, M., \& Zhou, M. (2011). Using LMDI method to analyze transport sector $\mathrm{CO}_{2}$ emissions in China. Energy, 36(10), 5909-5915. http://dx.doi.org/10.1016/j.energy.2011.08.031

Xu, B., \& Lin, B. (2015). Factors affecting carbon dioxide emissions in China's transport sector: a dynamic nonparametric additive regression model. Journal of Cleaner Production, 101, 311-322. http://dx.doi.org/10.1016/j.jclepro.2015.03.088

Xu, J.H., Tobias, F., \& Eichhammer, W. (2012). Energy consumption and $\mathrm{CO}_{2}$ emissions in China's cement industry: A perspective from LMDI decomposition analysis. Energy Policy, 50, 821-832. http://dx.doi.org/10.1016/j.enpol.2012.08.038

Zajac, P. (2011). The idea of the model of evaluation of logistics warehouse systems with taking their energy consumption under consideration. Archives of Civil and Mechanical Engineering, 11(2), 479-492. http://dx.doi.org/10.1016/S1644-9665(12)60157-5

Zhang, C., \& Yu, Z. (2012). Empirical Analysis on Economic Growth and Development of Logistics Based on the Cointegration and State Space Model. Science and Technology Management Research, 32(6), 222-225.

Zhang, H.B., \& Peng, Y. (2009). An Empirical Research on the Relationship Between Modern Logistics and Regional Economy Increase. Industrial Engineering and Management, 1, 122-126. 
Zhou, G., Chung, W., \& Zhang, X. (2013). A study of carbon dioxide emissions performance of

China's transport sector. Energy, 50, 302-314. http://dx.doi.org/10.1016/j.energy.2012.11.045

\section{Appendix A}

The LMDI formula for each factor in the decomposition analysis (see Table A1)

\begin{tabular}{|l|c|c|}
\hline \multicolumn{1}{|c|}{ Effect factors } & Multiplicative decomposition & Additive decomposition \\
\hline Logistics output(act) & $D_{a c t}=\exp \left(\sum_{i} \frac{\left(E_{i}^{t}-E_{i}^{0}\right) /\left(\ln E_{i}^{t}-\ln E_{i}^{0}\right)}{\left(E^{t}-E^{0}\right) /\left(\ln E^{t}-\ln E^{0}\right)} \times \ln \left(\frac{Y^{t}}{Y^{0}}\right)\right)$ & $\Delta E_{\text {act }}=\sum_{i} \frac{E_{i}^{t}-E_{i}^{0}}{\ln E_{i}^{t}-\ln E_{i}^{0}} \times \ln \left(\frac{Y^{t}}{Y^{0}}\right)$ \\
\hline Transport mode(str) & $D_{\text {str }}=\exp \left(\sum_{i} \frac{\left(E_{i}^{t}-E_{i}^{0}\right) /\left(\ln E_{i}^{t}-\ln E_{i}^{0}\right)}{\left(E^{t}-E^{0}\right) /\left(\ln E^{t}-\ln E^{0}\right)} \times \ln \left(\frac{S_{i}^{t}}{S_{i}^{0}}\right)\right)$ & $\Delta E_{s t r}=\sum_{i} \frac{E_{i}^{t}-E_{i}^{0}}{\ln E_{i}^{t}-\ln E_{i}^{0}} \times \ln \left(\frac{S_{i}^{t}}{S_{i}^{0}}\right)$ \\
\hline Transport intensity(intt) & $D_{a c t}=\exp \left(\sum_{i} \frac{\left(E_{i}^{t}-E_{i}^{0}\right) /\left(\ln E_{i}^{t}-\ln E_{i}^{0}\right)}{\left(E^{t}-E^{0}\right) /\left(\ln E^{t}-\ln E^{0}\right)} \times \ln \left(\frac{T^{t}}{T^{0}}\right)\right)$ & $\Delta E_{\text {intt }}=\sum_{i} \frac{E_{i}^{t}-E_{i}^{0}}{\ln E_{i}^{t}-\ln E_{i}^{0}} \times \ln \left(\frac{T^{t}}{T^{0}}\right)$ \\
\hline Energy intensity(inte) & $D_{\text {inte }}=\exp \left(\sum_{i} \frac{\left(E_{i}^{t}-E_{i}^{0}\right) /\left(\ln E_{i}^{t}-\ln E_{i}^{0}\right)}{\left(E^{t}-E^{0}\right) /\left(\ln E^{t}-\ln E^{0}\right)} \times \ln \left(\frac{I_{i}^{t}}{I_{i}^{0}}\right)\right)$ & $\Delta E_{i n t e}=\sum_{i} \frac{E_{i}^{t}-E_{i}^{0}}{\ln E_{i}^{t}-\ln E_{i}^{0} \times \ln \left(\frac{I_{i}^{t}}{I_{i}^{0}}\right)}$ \\
\hline Fuel mix(mix) & $D_{\text {mix }}=\exp \left(\sum_{i} \frac{\left(E_{i}^{t}-E_{i}^{0}\right) /\left(\ln E_{i}^{t}-\ln E_{i}^{0}\right)}{\left(E^{t}-E^{0}\right) /\left(\ln E^{t}-\ln E^{0}\right)} \times \ln \left(\frac{M_{i j}^{t}}{M_{i j}^{0}}\right)\right)$ & $\Delta E_{m i x}=\sum_{i} \frac{E_{i}^{t}-E_{i}^{0}}{\ln E_{i}^{t}-\ln E_{i}^{0}} \times \ln \left(\frac{M_{i J}^{t}}{M_{i j}^{0}}\right)$ \\
\hline Emission factor(emf) & $D_{\text {emf }}=\exp \left(\sum_{i} \frac{\left(E_{i}^{t}-E_{i}^{0}\right) /\left(\ln E_{i}^{t}-\ln E_{i}^{0}\right)}{\left(E^{t}-E^{0}\right) /\left(\ln E^{t}-\ln E^{0}\right)} \times \ln \left(\frac{U_{i j}^{t}}{U_{i j}^{0}}\right)\right)$ & $\Delta E_{\text {emf }}=\sum_{i} \frac{E_{i}^{t}-E_{i}^{0}}{\ln E_{i}^{t}-\ln E_{i}^{0}} \times \ln \left(\frac{U_{i j}^{t}}{U_{i j}^{0}}\right)$ \\
\hline
\end{tabular}

Table A1. Calculation formula of decomposition

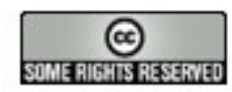

Article's contents are provided on a Attribution-Non Commercial 3.0 Creative commons license. Readers are allowed to copy, distribute and communicate article's contents, provided the author's and Journal of Industrial Engineering and Management's names are included. It must not be used for commercial purposes. To see the complete license contents, please visit http://creativecommons.org/licenses/by-nc/3.0/. 